\title{
Are We All in This Together? Alleviating the Childcare Constraint for Women in Economic Crises.
}

\author{
Abstract \\ Purpose \\ The purpose of this paper is to advocate the use of gendered economic policies to stimulate a post Covid-19 \\ recovery. We alert on the risk of ignoring the female dimension of the current crisis and of resorting again to \\ austerity programmes that, like the ones enacted after the 2008 crisis, would hit women and mothers \\ disproportionally harder than other groups.
}

\section{Design/methodology/approach}

We use data from the British Household Panel Survey on female participation and account for gendered constraints and enablers missed by mainstream economics. Using a sequential empirical approach, we simulate various welfare policy scenarios that address factors, such as childcare costs, personal and social nudges, that could help women back into the labour market in the aftermath of a crisis.

\section{Findings}

We found that incentive-type interventions, such as subsidies, promote female labour market participation more effectively than punishment-austerity type interventions, such as benefits' cuts. Policies oriented to alleviate childcare constraints can be sustainable and effective in encouraging women back to work. Considering factors wider than the standard economic variables when designing labour market policies may provide fruitful returns.

\section{Originality}

The sequential methodology enables the estimation of current and counterfactual incomes for each female in the sample and to calculate their prospective financial gains and losses in changing their labour market Status Quo, from not employed into employed or vice-versa. Welfare policies affect these prospective gains and losses and, by interacting with other factors, such as education, number and age of children and social capital, prompt changes in women's labour market choices and decision. 


\section{Introduction}

Crises elicit memories and stimulate reflections on the types of lessons learned from them. One of these lessons is that often the human, social and economic costs of a crisis fall unevenly upon communities: some groups bearing more significant personal and financial sacrifices. In 2019, the UN Special Rapporteur on Extreme Poverty and Human Rights confirmed again the structural disadvantages faced by UK women, and indicated that by 2021-2022, due to the austerity measures, the income of single parents ( 90 percent of whom are female), in the bottom quintile would drop 25 percent of their 2010 income, with a shocking associate jump in the poverty rate for children in single-parent households. Another lesson is that some governments' responses to crises can deepen pre-existing economic and well-being gaps. A third lesson is that social and economic systems do not react linearly to crises and shocks but develop hysteresis and complex patterns that make the future hard to predict. This health crisis is showing that it will not be different from past ones. There will be again groups shouldering disproportionate burdens. The young, women, and those in lower-paid jobs, will be more severely affected than others for their intersectionality with key service sectors and sectors in prolonged lockdown (Resolution Foundation, 2020). Evidence from a cross-country comparison using World Bank Data finds differential impacts of the COVID crisis on female labour market activity. The study finds the strongest link between reductions in labour market engagement in response to the need to look after children and home school during the COVID crisis. (Hyland, Djankov, and Goldberg 2020). Developed and developing economies will again face the risk of replicating past mistakes with policies that, if not carefully calibrated, can exacerbate the pre-crisis economic divides and consolidate persistent structural gaps. So, although our focus is on the United Kingdom, this issue is relevant to many other developed and developing economies.

Ten years ago, in the aftermath of the financial crisis, the then UK Chancellor declared "We are all in this together" (Osborn 2009) but robust empirical evidence demonstrated a different story. At the beginning of this crisis, the current UK Chancellor used the same quote, which triggered alarming memories. Will this time be different? Could past mistakes and austerity be avoided? These questions and concerns prompted our research. 
We believe that, despite a ten-year time lag, many constraints faced by women in the aftermaths of the 2008 financial crisis period, will re-emerge in the Covid-19 crisis, and that, now as then, women risk to shoulder an unequal share of the costs of the crisis. These beliefs urged us to use a gender lens of the past financial crisis as a warning and a reminder of the importance to resort to gender-budgeting policies to soften the economic burden of the current COVID-19 crisis on women, particularly on mothers, many of whom have compromised their financial security - in the short or in the long run- to look after their school-aged children. In this spirit, we used data collected in the aftermath of the 2008 financial crisis, before austerity policies worsened women's position, and identified constraints and enablers faced at that time by women in labour market decisions, many of which are likely to be at play today. We simulated policies that could have, to some degree, alleviated some of those burdens and helped non-working mothers to re-engage with the labour market. The ultimate goal of re-running the past is to alert for the future and to remind today's policymakers not to disregard this time, the needs, and experiences of those women who are among the more vulnerable groups of the society (Women's Budget Group, 2018; Trade Union Congress, 2015). This paper does not aim to compare the two recessions rather to use the evidence of the policy impacts of government response to the financial crisis recovery to ensure women are not double hit by a sherecession with enhance child-care responsibilities from home schooling and austerity-style policies. We therefore aim to promote the consideration of a gender budget approach in the post COVID recovery period.

This work builds on previous empirical results (Cagliesi et al., 2017, Cagliesi and Hawkes, 2013) but it focuses more sharply on women employment and non-working statuses, and it expands the dimensionality of women's decisions by enlarging the standard labour market model to include social, cultural and psychological factors in shaping women's opportunities and constraints. This interdisciplinary approach enables to gain useful policy insights that could inspire a more effective architecture of government interventions to alleviate women's increased vulnerability in periods of crisis.

\section{Stylised Facts: the pre-COVID world.}

The last 50 years have seen a global dramatic increase in participation of women in paid work. Table I reports the pre-financial crisis 2008 and pre-COVID crisis 2020 figures for the UK labour market. These numbers confirm a shift for women from inactivity (due mainly to caring responsibilities) and unemployment into employment (Office for National Statistics, 2019b). Since the financial crisis, the increase in employment has been particularly rapid and 
significant for women in couples, for women in their early $60 \mathrm{~s}$, and for those in the lowest income deciles, primarily single mothers.

<insert Table I here>

This job surge, however, has been associated with wage stagnation, rising State Pension age, welfare cuts, increase in the precariat, and longer hours at work (Resolution Foundation, 2019). In other words, households, particularly those with children and those on lower incomes, have reacted to real earnings reductions by suppling more work. For many this response has not always been enough to shield their finances. Shockingly, almost 60 percent of those in poverty in the UK are in families where someone works.

Among the workers, and despite some improvements, women are still experiencing lower pay than men, a higher concentration in part-time jobs, and more interrupted careers owing to care commitments (Castellano and Rocca, 2015). Often their dual roles, as workers and as primary caretakers of children, affects the type and quality of job they can access or aspire. In the UK, the percentage of non-working or part-time women' due to personal and family responsibilities' is almost twice as high as the European Union (EU) average (Council of the European Union, 2015), and working single mothers are almost twice as likely to be in low-paid, low-skilled employment with little chance of progressing than coupled mothers. In 2019, the UN Special Rapporteur on Extreme Poverty and Human Rights denounced the structural disadvantages faced by UK women, particularly by the single group, whose likelihood of experiencing persistent poverty was twice as high as any other group.

This reality combines with the very high cost of childcare -about $46 \%$ of women's gross median earnings - thus, for some women, especially lone parents, the cost of childcare can still be a significant barrier to entering the workforce. Research showed that those mothers who return to work bear a motherhood penalty (Kahn et al., 2014) - a pay gap and hiring disadvantages between working mothers and similar women without dependent children - which, in the $\mathrm{UK}$, is particularly acute at higher managerial levels.

\section{We are all in this together but unequally. The risk of a 'she-session' and of ignoring it.}


Giving these pre-existing gaps and gender inequality, how is the current crisis going to affect women's labour market choices and conditions? This current crisis that, for its unequal gender impact, has been termed 'Shesession' [1] has exposed women on two fronts: at work and home. At work, because, women, who are more likely to work in services and industry involving face to face interactions, have been hit harder by the crisis and face a much higher risk than men to lose or quit their jobs. At home, because in addition to sex segregation, "pink" sector crisis, or discrimination, many mothers have chosen to leave their jobs and look after their home-schooled children. Will they go back? This question is particularly concerning and relevant because, since 2000 and until the pandemic crisis, the rate of mothers in employment has progressively, overtaken the employment rates of women without dependent children, and even before the crisis 3 in 10 women with a child aged 14 years and under, reported they had reduced their working hours because of childcare reasons. This figure compared with 1 in 20 fathers (4.8\%) (Office for National Statistics, 2019a). Welfare policy that help women and mothers back to work could be a critical factor in reducing structural gaps in the UK and beyond (Castellano and Rocca, 2020; Shittu and Abdullah, 2019) and in accelerating the recovery.

For many women, working is a channel through which to gain autonomy, a sense of identity, status, and influence at home and in society. This opportunity ought to be preserved. For other women, staying at home is a genuine personal choice to be respected and not "stigmatized." It is essential to understand the difference between preserving freedom of choice and promoting social, personal, and economic well-being. The interdisciplinary approach that we propose acknowledges these different realities.

\section{Theoretical Framework: an Interdisciplinary Approach}

The traditional neoclassical analysis simplifies the complexity of women's labour market decisions reducing the process to a choice based on pecuniary considerations and the comparison of the opportunity cost of a non-working relative with the advantage of leisure. We believe that a good understanding of labour market choices would require a unified approach across different disciplines, and we propose a multidisciplinary approach that captures the interface of social and personal spheres. We depart from the utilitarian approach and consider insights from the Capability Approach (CA) proposed by Sen (1980) and from Behavioural Economics (BE). The CA sees any 
economic agent as being both socially embedded and individually free with a distinct identity. BE identifies psychological and cognitive biases that can explain why economic decisions depart from the rationality assumption.

The CA and social norm models have been used to study labour market decisions. Theoretical approaches, such as the segmented market theory (Bowles and Gintis, 1998, 2011), the human capital theory (Becker, 1976), and the Job Search and Information Models (Mortenson, 2003), and empirical studies (Burchardt and Le Grand, 2002; Clark, 2003; Akerlof, 1980) have considered and assessed the effect of social influence in labour market decision-making. However, in these models, the role of social influence has often been treated as a static external force rather than a dynamic interactive relational process (Granovetter, 1985), whose interplay with other behavioral and psychological factors, affects the decision-making process. The strength of specific individual relations (social ties) and the structure of the social network can influence labour market decisions (Goyal, 2007) via informational, motivational, and expectational effects. To gain useful insights into female labour market decisions, we control for social capital and interpersonal social relations (networks) factors.

The other crucial dimension to consider in the analysis is the personal capital. A large body of literature from BE and psychology presents evidence about people's choices that would not match the "economic-rational" paradigm. Prospect theory (Kahneman and Tversky, 2000) provides a cognitive decision-making framework that justifies "economic irrationality" on the grounds of the existence of some cognitive biases, on mutable emotional states, on different personality traits, on the effects of memories of past experiences (Kahneman and Krueger, 2006) and cultural factors.

We believe that our novelty approach to consider the interplay of social, psychological, economic factors in labour market decisions could help design more informed public sector policy and successful nudges (Oliver, 2013).

\section{An Empirical Multidisciplinary Approach: Methodology and Variables}

In this study, we used a two-step approach: in the first step, we used an endogenous switching regime model to estimate labour earnings of employed females, non-labour earnings of non-employed females and their counterfactuals. In the second step, we used a Multinomial Probit model to estimate the probabilities of three labour 
market categories: inactive non-working carers (mothers), unemployed and employed females. The data set used to test our hypotheses is the 2009 wave of the BHPS (British Household Panel Survey). As explained earlier, we selected 2009 as this was the last period when the UK economy was in a weakened state and before the austerity drives of the conservative and the previous coalition governments of 2010-2020 policy options for the labour market recovery post-COVID. The sample composition is explained in the Appendix.

\section{The Econometric Models}

Our first model is an endogenous switching regime model of labour and non-labour earning equations with a criterion equation, which determines in which regime (employment versus non-employment) an individual could be. This model produces estimates of factual and counterfactual incomes of each individual (such as the working earnings of a non-working female if she became employed, and the non-labour earning of a working female if she did not work) and enables to calculate the prospective financial gains and losses of changing the labour market Status Quo, from not employed into employed or vice-versa. To test if people act more to avoid losses than to obtain gains (the loss aversion principle of Prospect Theory, in BE), we separated prospective gains (Prospectpos) and prospective losses (Prospectneg). The former includes only prospective financial gains (e.g., the increase in income if a female switched from non-working into employment), and the latter includes only prospective financial losses. A difference in their coefficients would indicate the differential (asymmetric) effects of facing prospective financial gains in becoming employed. The results of the switching regime model are reported in the Appendix [2].

In the second step, we use a Multinomial Probit model, to estimate the probabilities of a woman being non-working carer, unemployed, or employed, while controlling for several variables. This model has the following form:

1)

$$
P_{i m}=\operatorname{Pr}\left[Y_{i}=m \mid L M V_{i}, B_{i} V_{i}, f\left(P R O S P E C T N E G(P O S)_{i}\right), S_{a t V_{i}}, S_{N}, \text { INTERACTION }_{i}\right]
$$

Where:

$\mathrm{P}_{i m}$ is the probability for individual $i$ to fall in the category $m$, with $\mathrm{m}=1,2,3$ and with $1=$ non-working carers, 2=unemployed, $3=$ employed (reference category);

$L M V_{\mathrm{i}}$ is a set of labour market variables for individual $i$;

$B E V_{\mathrm{i}}$ is a set of behavioural variables for individual $i$; 
$f\left(P R O S P E C T N E G(P O S)_{i}\right)$ is the value function of prospective financial losses (Prospectneg) or gains (Prospectpos) faced by individual $i$ when changing status from worklessness into employment (or viceversa) and are obtained from the estimates of the switching model [3];

$\operatorname{Sat} V_{\mathrm{i}}$ is a set of subjective wellbeing variables for individual $i$;

$S N V_{i}$ is a set of social relations and network variables for individual $i$;

INTERACTION $_{i}$ is a set of interaction terms of social and personal factors for individual $i$.

Some of the variables we used in our estimates were directly available from the survey; others had to be created as combinations of answers to questions in different parts of the questionnaire. We organized them in "direct factors" and "interaction terms," and we limit here our description to the ones that turned out to be statistically significant in the Multinomial Probit model while referring the interested reader to Cagliesi and Hawkes (2013) for a full description of all the variables created for the two-stage estimation process and for more detailed explanation for the theoretical links.

\section{Variables: Direct Factors}

In line with the CA approach, we propose to use three categories of factors (personal characteristics, psychological factors, and social factors) that, acting either as constraints or enablers, can affect a woman's opportunity and choices. The first set of factors are grouped under the umbrella of "labour market variables or human capital factors" since they typically are included in standard labour market models. These variables are age, education, employment history, parents' employment and non-employment status, physical condition, marital status, number and age of children.

The second set of factors includes variables that capture BE principles (such as loss aversion, self-esteem, and confidence), variables that reflect personal beliefs and values regarding jobs and family, and variables that are related to psychological traits and subjective perception of wellbeing. These attributes are derived from different sections of the BHPS, and higher values indicate a stronger presence of the attribute.

The third set refers to the respondents' social characteristics, social capital (the closest three friends and their labour market statuses), and the strength of embeddedness and social relations (having local friends, belonging to the neighborhood, etc.). Social norms and "close ties" represent vital additional elements of the analysis. 
In the CA spirit, we also included a set of variables related to opportunities and capabilities such as current access to or ownership of goods and services (such as access to a car, the internet, ownership or shared ownership of a house, ownership of a mobile phone, satellite, and landline).

\section{Variables: Interaction Terms. Labour Market "Social Network Norm" and Personal Views}

We were interested in checking if the labour market decisions of close friends could reinforce or weaken motivation and efforts in finding employment. To test these hypotheses, we extended Akerlof's work (1980) and created some interaction terms that should capture the intersectionality between the social sphere and the personal sphere.

The first interaction term (GinterACTtie) is a dummy variable that identifies respondents whose three closest friends (strong ties) are all labour market active (employed or unemployed). This condition may act as an enabler to move into employment. The second type of interaction is between the labour market status of the three closest friends (all employed versus some or all not unemployed) with the respondent's working ambitions (attributing a very high versus very low importance to having a fulfilling job). Out of the four possible dummies, only the two linked to lack of job ambitions turned out to be relevant for non-employed women. The first dummy (Conform to a non-working network) represents the case of a not job-ambitious woman with some or all non-working friends. The other relevant dummy is Deviate from a working network, and it represents the case of a not job-ambitious woman, but this time all of her closest friends are employed. The statistical relevance of these two specific dummies in our estimates and the irrelevance of one of the other two would suggest that lacking job ambitions (i.e., having a more emotionally detached "personal disposition" towards the labour market) are a significant constraint for a non-working female to switch into employment. The difference in their coefficients could indicate if, given that disposition, the types of the network can make a difference.

\section{Results}

Table II reports the statistically significant coefficients of the Multinomial Probit regression. As expected, having young children and being a lone parent are significant constraints, ameliorated by higher education. Prospective 
financial gains incentivize a non-working mother and unemployed females to become employed, while prospective financial losses discourage a change of the status quo. Moreover, following the predictions of prospect theory, these effects are asymmetric, and the reaction to an economic loss is bigger than the reaction to an equivalent economic gain.

< insert Table II here>

Non-working carers are also affected by BE and social variables: stronger family life values, loss of self-confidence, and a higher degree of embeddedness in the local community (particularly in communities characterized by high levels of non-employment) are all factors that increase the probability of a non-working mother status. On the other hand, having stronger ties with labour market active close friends, having more availability of capabilities (such as a house, a car, the internet, a mobile phone), and personality traits such as conscientiousness, are all factors that increase the probability of a working status.

Personal stance towards the labour market plays a role: lacking job-ambitions (having a more emotionally detached labour market attitude) results in a higher probability of becoming a stay-at-home carer, even when surrounded by employed close friends. It may become more difficult to engage these women, and policies here should aim to nudge a change in the attitude, to instill self-confidence, and to offer mentorship, betterment, and training opportunities.

We computed marginal effects (MES) for selected predictors (such as children, preferences, and prospective gains and losses). Table III shows that having more children below school age is a significant constraint, that considerably increases the probability of being a non-working mother if a woman is a single mother with no higher education. The child constraint seems less strong for higher-educated women.

< insert Table III here>

Table IV shows that people respond more to a decrease in financial losses than an increase in financial gains. This finding is in line with Prospect Theory prediction that people strongly prefer avoiding losses to acquiring gains and it has the following implication. Some at-home women would be financially better off if employed. However, some others would face prospective losses. These losses could arise either because these women expect to be in a low-paid job or because they expect to work for a few hours. A reduction of these losses (such as a better-paid job or the 
possibility of working longer hours) would represent for these at-home females a bigger incentive into employment than an equivalent increase in gain would represent for other at-home females.

The asymmetry of the reaction to losses and gains depends on two factors: personal attitude and the magnitude of losses and gains. Among the at home cares, the job-ambitious women, when compared to the non-job ambitious ones, display a stronger reaction to high losses (in the 10th and 25th percentile of the distribution) and a much lower reaction to gains. In the domain of gains, this last feature can be a trait of those non-working mothers who have taken maternity leave and plan to return to work in the future. In this scenario, additional gains into employment do not stimulate strong reactions because these women prefer to be temporarily at home. On the other hand, the nonworking and more emotionally detached carers are more reactive to an increase in the financial gain of switching into working, possibly because their status is less due to choices and more due to lack of opportunities. In the domain of losses, the opposite occurs: those at-home carers with job ambitions reacts to the same reduction of financial losses more than the at-home ones more emotionally detached would.

< insert Table IV here>

Therefore, financial incentives matter but they interact with personal attitudes and ambitions. A policy that accounts for these personal drivers may, therefore, be more impactful. The policy should aim to engage and motivate the more detached to reinforce the effect of the financial incentives of a switch into employment, particularly when the switch may lead to a loss of income. At the same time, the policy should help the transition back into work when the non-working status is a temporary choice following the maternity experience, and women are motivated and engaged with the labour market.

\section{Simulations of Policy Scenarios}

Building on the model above, we generate policy scenarios to consider the female labour market constraints and identify female-focused incentives to support mothers in the return to work after the COVID she-session and homeschooling impact. We used the Probit estimates to perform simulations of welfare policies to gain insights into what 
could nudge non- working mothers into participation. We devised three simple policies (indicated as Cut, Benefit and Child policy) and two combinations (called Mixl and Mix2). These policies represent a simplified version of reality.

The Benefits policy could be viewed as the New Labour's attempt to make work pay through the tax credits system. This policy would provide an additional $£ 100$ per week to the labour income of those working females with children aged 0 to 12 who are single parents or whose partner is not employed. It provides a "positive" incentive and resources to reward employment status. The $C u t$ policy could reflect the coalition government's attempts to reduce the dependence on welfare. It creates a negative incentive that would prompt a change in the status quo of those nonworking female with children aged 0 to 12 , and who are single parents or with a non-working partner if they wanted to avoid a weekly loss of $£ 100$ of the non-labour earnings.

The Child benefit policy is about alleviating the childcare constraint. It is a "positive" policy, tailored to working females with children aged 0 to 15 and with a labour income below $£ 26,000$. The policy is more "personal" because it provides resources according to the number of children and their age [4]. The childcare policies of New Labour's Sure Start of and Working Families tax credits childcare components are real work examples of this child-based simulation and form the basis of the idea behind this simulation. The policy Mix 2 is the mix of the child policy and the cut policy. The reason for devising a mixed policy is to reduce the cost of the policy for the government, therefore making it more sustainable.

These simulations are relevant as the debate about the most effective economic recovery approach from COVID-19 heightens. Because we use 2009 data, right after the financial crises, these simulations provide us with a baseline to test the potential effect of repeating past mistakes facing a weakening. Before presenting our simulation, it is important to stress that the two incentive policies, Benefit, and Child, are not directly comparable because of the following two reasons: firstly, the Child benefit policy "falls" on a larger group of women, of whom the females eligible for the benefits policy are a subset; secondly, they involve different amounts of resources. However, the percentages of non-working women eligible for the Benefit policy, and hence for the Child policy, and gain from either policies in switching status, are not dissimilar (50\% for Benefit and 43\% for Child), meaning that for some non-working women the two policies did not differ much. Despite this similarity, the more meaningful comparisons 
are between Benefit and Cut policies and their mix (Mixl) (because they fall on the same group of women and are of the same amount) and the Child and Mix2 policies.

Table V reports the overall results of the simulations and the baseline scenario (no policy) and the average probability of the entire sample and of the sub-sample of mothers ( $47 \%$ of the sample), for whom policies are designed, independently of the actual market labour status of the respondents. Our results are in line with Blundell et al., (2016), who, using the Labour Force Survey, find tax credits to be welfare-enhancing for women in the UK, especially mothers.

Three main observations can be drawn from the table: firstly, policies affect only minimally the average probability of being unemployed, but they affect the average probability of the other two categories; secondly, monetary incentives affect the probability of being an at-home more than monetary punishments of an equivalent amount do, as shown by the slightly higher average percentage of being at-home carers under the Cut policy relative to the Benefit policy. Despite the small difference between benefit and cut policies, these two policies can potentially produce very different effects on child poverty, an aspect that is not included in the analysis, but that must be considered in comparing these policies. Thirdly, mixed policies always produce stronger results because they combine the effects of policies working in the same direction. [5]

< insert Table V here>

To better understand the effects of policies, in the rest of the paper, we focus on mothers, as they are the females to whom policies are directed, and we control for some specific factors. Mothers who are more emotionally detached from the labour market (Figure 1), or with young children aged 0-4 (Fig. 2) have a higher probability of being athome carers, and a higher responsiveness to policy, than mothers with opposite characteristics.

< insert figure 1 here>

<insert figure 2 here>

In Figure 3 we consider only mothers who are currently at-home carers. The figure illustrates, for these women, incentives work better than punishments in prompting them closer to the labour market and into employment. The Child policy and Mix2 are very effective in altering probabilities, making employment more likely than keeping the status quo. 
< insert figure 3 here>

We control for some additional personal factors such as the number and age of children, labour market attitude and prospective gains and losses, and education (Fig. 4-7), and we focus only on the Child policy, as this is the one effective in alleviating the children constraint.[6] Figure 4 reveals that the at-home mothers with pre-school age children (particularly for the three to four years old age group) benefit the most from the policy; the weakest effect of the Child policy is shown by the category of carers with older children (aged 12 to 18). This result is not surprising because older children of working age would represent a less stringent parenting constraint than a younger child. What is surprising instead is that the non-working mothers of older children show the highest probability of keeping their status quo. Two factors may explain this position: either a generational reason or the difficulty of returning to the labour market once children have grown.

$<$ insert figure 4 here>

Figure 5 combines information about parenting constraints and personal labour market attitudes. Some observations can be made. Firstly, in the absence of a policy, mothers with job ambitions do not seem to be particularly constrained by having younger or older children. The baseline figures show that valuing a rewarding job almost annul the young children's constraint, as all mothers show a similar conditional probability of keeping the status quo. However, under the Child policy the situation changes. The mothers of pre-school children are those most affected by the intervention, and they see their probability of keeping the status quo halved by the policy.

$<$ insert figure 5 here >

Secondly, for mothers without job ambitions the situation is quite different and having pre-school children represents a bigger constraint than not having them. These mothers show the highest probability of keeping their status quo in the absence of policy. Overall, the group mostly affected by the Child policy is the one of mothers of pre-school children with positive job ambition attitude, which may reveal a willingness to engage with the labour market. The least reactive group is the group of mothers of older children and detached preferences (this is the group most challenging to engage in the labour market because as already pointed out, they may be "discouraged" nonworking female who may have found it difficult to re-engage with the labour market after children have grown).

Figure 6 illustrates the probabilities of at-home mothers with different job market attitudes, facing different sizes of prospective gains and losses in changing the status quo under the no policy scenario. The first two quartiles include 
only losses; the third quartile includes both losses and gains, the last quartile only gains. The effects of the Child policy are much stronger in the first two quartiles when the policy reduces losses (or changes losses into gains) than when it adds extra gains to existing ones. This result is even more pronounced in the presence of job market ambitions.

<insert figure 6 here>

The last figure (Fig. 7) illustrates the combined effect of education and having children aged 0-12.

< insert figure 7 here>

The graph prompts three observations. Firstly, under any scenario, the lowest probability of being at-home mothers is associated with highly educated mothers of older children. On the other hand, the highest probability is associated with the non-highly educated mothers of older children, who may find it more difficult or less financially rewarding to re-enter the market after the children have grown.

The second observation is that, under the baseline scenario, having or not having young children makes only a small difference for the non-highly educated at-home mothers. The opposite occurs to the highly educated ones, for whom having young children represents a crucial constraint that doubles their probability of being at-home compared to the case of highly educated mothers without young children.

The third observation is that the Child policy helps to alleviate the "young children" constraint. It seems to prompt the highly educated at-home mothers to reconsider the returns on their educational investment and the opportunity cost of slower career progression. And it seems to help the low-skilled ones by making it worth to accept a low paid job.

Overall, the Child Policy appears to achieve the following two things. Firstly, by "compensating" for the lack of higher education, it could help "align" the less educated mothers more closely with the highly educated groups. Secondly, by reducing the "young child" constraint, it could help close the gap created by the children's age within the group of the more educated mothers.

\section{Policy Implications and Conclusions}

Motherhood creates a significant economic disruption to female labour participation and women's careers. 
Nurturing female talent is paramount if we aim to be an economically competitive nation and a gender unbiased society. This need is especially real at times of economic shocks, such as the financial crisis in 2009 and the significantly worse impact of the global economic shock of COVID-19 as the impact on the labour market for mothers has been particularly affected by the types of jobs impacted in the she-session, the amplification of the impact of childcare due to home schooling and job protection policies that have been more protective of jobs for men than women Francis-Devine, Powell and Foley (2021).

Our key findings are:

(1) Prospective financial gains incentivize a non-working mother and unemployed females to become employed, while prospective financial losses discourage a change of the status quo. These effects are asymmetric, and the reaction to an economic loss is bigger than the reaction to an equivalent economic gain.

(2) Given these responses to prospective financial gains and losses, policies that support the financial costs of returning the labour market, such as in work benefits and child care subsidies, are more effective than benefit cuts for mothers.

Progress for mothers was made, especially in the spell 1997-2010, when the New Labour Government Policies supported women through the practicalities of motherhood. Many of these supports were lost in the Austerity Period 2010-2020. Therefore, the economic recovery from COVID-19 for female employment needs more focus than in 2009 , given the depth of the global recession to come and given the lower level of state support for women to engage in the labour market in the post-Austerity period. More extended and more generous maternity leave, flexible working hours, and part-time schemes are now available, and the UK government has introduced a paternity leave programme to share parental child-rearing responsibility. Many women, however, do not seem to benefit from these facilities. Fully, and more "targeted" interventions are needed. For instance, for the higher-skilled women who can afford expensive childcare, the obstacle in the advancement of their post-motherhood career often resides in the corporate stigmatisation of flexible and part-time work, which is perceived as lacking ambition and commitment. Encouraging and firmly nudging fathers into paternity leave (Chile, Italy, and Portugal have compulsory paternity leave) may eventually lead to altering these perceptions and correct managers' bias against advancing and promoting women in their careers. 
Other schemes can be envisaged to help women back after a mid-career break. Wall Street and India have pioneered "returnship" schemes to bring experienced women back into the workforce via paid programmes, conceived as a combination of a mid-career internship and a fixed contract. Another initiative to put women on a par with men across higher-skilled careers is to pair women who have taken a career break with more experienced mentors. However, for the lone parents and lower-paid women, paternity leave and "returnships" or "mentorships" may not be viable options. For them, childcare affordability is paramount. With the return to school and the end of furlough scheme in the UK, this provides an opportunity for employers to co-design mother-friendly return to work policies (or work from home policies) to maintain their valued workers.

Failing to address the cost of childcare is a severe policy shortcoming that affects both women's and men's working opportunities and, most crucially, children's development.[7] Childcare costs more in the UK than in any other European country except for Switzerland and Ireland. The British government has shown an awareness of the problem in doubling the hours, from 15 to 30 , of free nursery care to eligible working parents of children aged three or four. More can be done in terms of public policy to increase access to affordable childcare while securing its quality. Restructuring the tax system to allow families to claim tax credits against the cost of childcare and tackle the inadequate supply of provision around the UK could help to ameliorate the issue of access to childcare.

The UK responses to previous spells of mass unemployment have mainly focused on the number of people unemployed and reserved marginal attention to its composition and people hidden in other worklessness statuses. The "We are all in together" promise should be kept better than in the past, and the design of current and future policies should recognize and address specific gender needs. The COVID-19 crisis has made us more aware of the challenges of juggling professional and parental roles, and the months of lockdown have demonstrated to which extent the economy relies on unpaid care, an aspect that is ignored in economic modelling and policymaking. At this time, with governments around the world combating a global economic shock, it is vital to present evidence on possible economic recovery plans that are focus on women's employment and childcare cost support. Our results show that gendered policies can support female employment even at difficult times if policymakers design these policies with women in mind. 


\section{References}

Akerlof, G. A. (1980), “A Theory of Social Custom, of Which Unemployment May Be One Consequence”, The Quarterly Journal of Economics, Vol. 94 No. 4, pp.749-775.

Becker, G.S. (1976), The Economic Approach to Human Behaviour, University of Chicago Press, Chicago, IL.

Blundell, R., Costa Dias, M., Meghir, C. and Shaw, J., (2016), "Female Labour Supply, Human Capital and Welfare Reform”, Econometria, Vol. 84 No. 5, pp. 1705-1753.

Bowles, S. and Gintis, H., (1998), "Is Equality Passé? Homo Reciprocans and the Future of Egalitarian Politics”, Boston Review, Vol. 6, pp. 4-35.

Bowles, S. and Herbert Gintis, H., (2011), Schooling in Capitalist America, Haymarket Books, Chicago, IL.

Burchardt, T. and Le Grand, J., (2002), “Constraint and Opportunity: Identifying Voluntary Non-employment” , working paper, Centre for Analysis of Social Exclusion, London School of Economics and Political Science, London.

Cagliesi, G. and Hawkes, D., (2013) "What Nudges Will Matter? An Empirical Study of Female Joblessness", working paper, The Business School Working Paper Series, CEPGR, University of Greenwich, London.

Cagliesi, G., Hawkes, D. and Tookey, M. (2017), “A Multi-disciplinary Approach to Explaining Workless-ness in Britain”, International Journal of Social Economics, Vol. 44 No. 7, pp. 937-959.

Castellano, R, and Rocca, A. (2015), “Assessing the Gender Gap in Labour Market Index: Volatility of Results and Reliability”, International Journal of Social Economics, Vol. 42 No. 8, pp. 749-772.

Castellano, R, and Rocca, A. (2020), “On the Unexplained Causes of the Gender Gap in the Labour Market”, International Journal of Social Economics, Vol. 47 No. 7, pp. 933-949.

Clark, A.E. (2003), “Unemployment as a Social Norm: Psychological Evidence from Panel Data.” Journal of Labour Economics, Vol. 21 No. 2, pp. 323-51.

Council of the European Union (2015), Employment, Social Policy, Health and Consumer Affairs Council. EPSCO.

European Commission (2014), Report on Equality between Women and Men 2014. Brussels: European Commission Francis-Devine, B., Powell, A, Foley, N (2021) Coronavirus: Impact on the Labour Market, House of Commons Library, Briefing Paper, Number 8898, 25 February 2021: UK

Gammage, S., Joshi, S. and Rodgers, Y. (2020), “The Intersection of Women's Economic and Reproductive 
Empowerment", Feminist Economics, Vol. 26 No. 1, pp. 1-11.

Hyland, M, Djankov, S. and Goldberg. P. (2020), "Gendered Laws and Women in the Workforce." American Economic Review: Insights, 2 (4): 475-90.

Goyal, S. (2007), Connections: an Introduction to the Economics of Networks, Princeton University Press, Princeton, NJ.

Granovetter, M.S. (1985), “Economic action and social structure: the problem of embeddedness”, American Journal of Sociology, Vol. 91 No. 3, pp. 481-510.

Himmelweit, S.F. and Sigala, M. (2004), “Choice and the Relationship between Identities and Behaviour for Mothers with Pre-School Children: Some Implications for Policy from a UK Study”, Journal of Social Policy, Vol. 33 No. 3, pp. 455-478.

Kalish, Y. and Robins, G. (2006), "Psychological Predispositions and Network Structures: the Relationship Between Individual Predispositions, Structural Holes and Network Closure”, Social Networks, Vol. 28 No. 1, pp. 5684.

Kahn, J., Garcia-Manglano, J. and Bianchi, S. (2014), “The Motherhood Penalty at Midlife: Long-Term Effects of Children on Women's Careers", Journal of Marriage and Family, Vol. 76 No. 1, pp. 56-72.

Kahneman, D. and Krueger, A. B. (2006), “Developments in the Measurement of Subjective Well-Being”, Journal of Economic Perspective, Vol. 20 No. 1, pp. 3-24.

Kahneman, D. and Tversky, A. (2000), Choices, Values, and Frames, Cambridge University Press, Cambridge, UK. Mortenson, D. T. (2003), Wage Dispersion: Why Are Similar Workers Paid Differently? MIT Press, Cambridge, MA.

Office for National Statistics (2019a), Families in the Labour Market,. ONS, London, UK.

Office for National Statistics (2019b), Economic Inactivity by Reason INAC01SA, ONS, London, UK.

Oliver, A. (2013), "From Nudging to Budging: Using Behavioral Economics to inform Public Sector Policy", Journal of Social Policy, Vol. 42 No. 4, pp. 685-700.

Osborne, G. (2009) "We will lead the economy out of crisis" Conservative Party Speech, October 2009 https://conservative-speeches.sayit.mysociety.org/speech/601293

Resolution Foundation (2019), Feel Poor, Work More Explaining the UK's Record Employment, Resolution Foundation, London, UK. 
Resolution Foundation (2020), Risky Business. Economic Impacts of the Coronavirus Crisis on Different Groups of Workers, Resolution Foundation, London, UK.

Seguino, S. (2020), "Engendering Macroeconomics Theory and Policy", Feminist Economics, Vol. 26 No. 2, pp. 27-

61.

Sen, A. (1980), “Equality of What?", Sen, A. (Ed.), Choice, Welfare and Measurement, Blackwell, Oxford, UK.

Shittu, W.O and Abdullah, N. (2019),"Fertility, Education, and Female Labour Participation. Dynamic Panel

Analysis of ASEAN-7 countries", International Journal of Social Economics, Vol. 46 No. 1, pp. 66-82.

Stewart, K. (2014), “Employment Trajectories and Later Employment Outcomes for Mothers in the British

Household Panel Survey: An Analysis by Skill Level”, Journal of Social Policy, Vol. 43 No. 1, pp. 87-108.

Trade Union Congress (2015), The Impact on Women of Recession and Austerity, TUC, London, UK.

UN Special Rapporteur (2019), UN Special Rapporteur on Extreme Poverty and Human Rights UK Visit, United

Nation Human Right, New York, NY.

Women's Budget Group (2018), The Female Face of Poverty Examining the Cause and Consequences of Economic

Deprivation for Women, Women's Budget Group, London, UK.

Endnotes

[1] The term 'she-session' has been used to describe the COVID induced recessions, which differs from the 1990s and 2000s recessions because it hits female-dominated sectors.

[2] Because our focus is on policy, we omit the discussion of the results of the switching model. This model has also been estimated to check for the impact of part-time working, considering both those working under 20 hours and those working 20-35 hours.

[3] Following the BE approach, the variables Prospectpos and Prospectneg are arguments of an S-shaped value function that allows for diminishing sensitivity to losses and gains by including linear and non-linear term.

[4] The policy would provide a weekly benefit of $£ 250$ for any child aged (0-2); £100 for any child aged 3-5; £25 for any child aged $5-11 ; £ 10$ for any child aged $12-15$.

[5] We simulated different interventions (cuts and benefits of $£ 2600$, cuts, and benefits of $£ 10,400$ ). We still found a higher sensitivity to benefits than to cuts. More substantial interventions would progressively (but not drastically) reduce the average probabilities of being at-home carers and increase the probability of becoming labour market active.

[6] The purpose of the exercise of including Benefit and Cut policies was to show that people react to incentives more than to punishment of the same size.

[7] In Europe, the interventions of the European Structural and Investment Funds (ESIF), European Social Fund (ESF) and European Regional Development Fund (ERDF), successfully increased the places in childcare facilities and helped reconcile work and family life. 